\title{
Classroom Assessment Techniques: An Assessment and Student Evaluation Method
}

\author{
Dawn-Marie Walker \\ University of Nottingham, Nottingham, UK \\ Email: dawn-marie.walker@nottingham.ac.uk
}

Received August $9^{\text {th }}, 2012$; revised September $10^{\text {th }}, 2012$; accepted September $24^{\text {th }}, 2012$

\begin{abstract}
Some of the challenges that face Higher Education are how to ensure that assessment is meaningful and that feedback is prompt in order to promote learning. Another issue is how to provide lecturers with feedback regarding their efficacy, in a timely and non-judgmental manner. This paper proposes that Classroom Assessment Techniques (Angelo and Cross, 1993), maybe a good way of answering both of those issues. They are quick and easy tasks set within the lecture, which tests the students' knowledge, providing an immediate opportunity for further elaboration if needed by the lecturer, therefore providing immediate feedback to the students. It also ensures that the lecturer has delivered the most salient messages, therefore also providing feedback to the lecturer.
\end{abstract}

Keywords: Assessment; Student Evaluation; Feedback; Classroom Assessment Techniques

\section{Introduction}

Appropriate assessment in Higher Education (HE) is a topic which has been debated and researched over the years, as not only is assessment respected as a necessary method of quantifying students, but it is also required by clients themselves, both students and employers. One of the major problems with assessment is how to make it meaningful, and in a manner which promotes deep learning to develop independent and self motivated thinkers, whilst also fulfilling the assessment criteria. This is often achieved by providing thorough feedback in a timely manner after the assessment, which in large classes can be difficult to the lecturer. Another area of much debate in HE is how to evaluate what is taught. Student evaluation of teaching and modules is prone to criticism; therefore many suggestions of evaluation methods to improve accuracy have been put forward. The present paper aims to draw on previous theories about: 1) assessment, i.e. summative or formative; 2) feedback; and 3) student evaluated teaching, to propose an assessment method, which also combines an evaluation method.

\section{Approaches to Learning}

The deep approach to learning which is what HE strives to achieve, involves the critical analysis of new ideas, with the student relating their own previous knowledge to the new knowledge, theoretical ideas, and evidence. This in turn leads to understanding and long-term retention of concepts so that they can be used for problem solving in unfamiliar contexts. The surface approach to learning is the unquestioning acceptance and memorization of information as isolated and unlinked facts which lead to rote learning for examinations, most of which are promptly forgotten about following the exam (Marton \& Saljo, 1976; Biggs, 1987; Biggs, 1993; Ramsden, 1992), i.e. "brain dump”. Deep learning is driven by challenging, open-ended problems with lecturers acting as facilitators in an interactive classroom. An interactive classroom promotes deep approaches to learning and contributes towards positive student motivation by allowing students to be in charge of their learning environment (Markett et al., 2006). A key strength of classroom interaction is that it provides scaffolding which allows the student to develop content into context, therefore developing cognitive structures (Moore, 1989). Therefore to promote deep learning, there has to be dialogue and an interactive classroom, and also great care needs to be given when choosing assessment techniques to prevent surface learning (Table 1 compares and contrasts these two approaches to learning).

\section{Assessment}

Assessment can provide a framework for sharing educational objectives with students and for mapping their progress. For these reasons there is strong support for assessment to be part of the learning process (Dochy \& McDowell, 1997). In general, assessment is divided into two concepts: formative and summative. Formative assessment is intended to assist student learning via deep learning approaches. Summative assessment on the other hand, e.g. assessments involving short questions, multiple choice or unseen exams, checks the level of learning at the end of a course/module and often takes the form of an exam or piece of course work which is graded. Exams lend themselves to rote learning, or surface approaches by encouraging students to concentrate on performance goals (passing the test) rather than learning goals (understanding the subject) (Dweck, 1999). This leads some to argue that summative assessment in itself can control, and arbitrarily classify students whilst impairing the student's own sense of self and leads to a limitation of their educational development (Barnett, 2007). Therefore it is argued that formative assessment should be an integral part of teaching and learning in HE and that it should be systematically embedded in curriculum practices (Juwah et al., 2004).

To optimize the learning from the assessment procedure the marking criteria for that assessment should be transparent and explicit, as this will enable students to understand what is re- 
Table 1.

Compare and contrast deep learning with surface learning (based on Ramsden, 1992).

\begin{tabular}{|c|c|}
\hline $\begin{array}{l}\text { Deep learning } \\
\text { Takes a broad view }\end{array}$ & $\begin{array}{c}\text { Surface learning } \\
\text { Takes a narrow view }\end{array}$ \\
\hline Looks for meaning & Relies on rote learning \\
\hline $\begin{array}{l}\text { Focuses on the concepts and } \\
\text { arguments to solve the problem }\end{array}$ & $\begin{array}{l}\text { Focuses on the formula to solve } \\
\text { the problem }\end{array}$ \\
\hline $\begin{array}{l}\text { Relates new knowledge to } \\
\text { previously learnt knowledge }\end{array}$ & $\begin{array}{c}\text { Focuses on learning unrelated bits } \\
\text { of a task }\end{array}$ \\
\hline $\begin{array}{c}\text { Relates knowledge across mod- } \\
\text { ules/courses }\end{array}$ & $\begin{array}{l}\text { Information is memorized solely } \\
\text { for assessment }\end{array}$ \\
\hline Relates theory to practice & $\begin{array}{c}\text { Theory is not reflected upon in } \\
\text { real life }\end{array}$ \\
\hline $\begin{array}{l}\text { Evidence and argument between } \\
\text { theories is developed }\end{array}$ & $\begin{array}{c}\text { No cross referencing between } \\
\text { theories }\end{array}$ \\
\hline Emphasis is student centered & $\begin{array}{l}\text { Emphasis is external, i.e. } \\
\text { assessment driven }\end{array}$ \\
\hline
\end{tabular}

quired of them to gain a top mark and enables them to gain feedback, via reflection on their own work when compared with the criteria, and so will encourage deep learning (Norton et al., 2001). Feedback is an extremely important part of learning and the assessment process. For any assessment to be useful to the student in their personal development there needs to be a timely feedback loop that will encourage the student to learn from the process, to reflect on their work and to assimilate the knowledge for future practice. When assessment (often formative) encompasses a feedback loop, it results in positive benefits on learning and achievement across all content areas; knowledge, skills and levels of education (Black \& William, 1998).

\section{Feedback}

Feedback is information about how the student's present state (of learning and performance) relates to the desired goals and standards (Nicol \& Macfarlane-Dick, 2006) and systematic reviews show that effective feedback leads to learning gains (Black \& William, 1998). Lecturer feedback serves as an authoritative external reference point against which students can evaluate, and self-correct their progress and their own internal goals (Juwah et al., 2004). Hence the main aim of feedback is in developing self regulated students, which requires them to internalize personal goals against which their performance can be compared and assessed by themselves (Nicol \& MacfarlaneDick, 2006). However providing meaningful feedback in a timely manner can be difficult. Although there has been expanding numbers of students attending HE, the actual resource allocated per student in the largest classes may be much less than ten years ago (Gibbs, 2006). The work load of lecturers is often calculated by "class contact hour" which ignores class size, therefore assessment loads are sometimes ignored (Gibbs, 2006). These time constraints, together with modularization of degrees, often without any increase in staffing, can increase the utilization of summative assessment (Gibbs, 2006) and therefore leads to a decrease in timely and relevant feedback which would have enhanced learning.

It is also important that the feedback is in a loop and is part of a dialogue which encourages engagement. Dialogue between the lecturer and student will help develop the student's under- standing of expectations and standards, to correct misunderstandings and to get an immediate response to difficulties (Freeman \& Lewis, 1998). It can also inform the lecturers as to whether they are teaching appropriately and whether it is at the right level, therefore providing an immediate opportunity for realignment of their teaching. A common method of closing the loop and providing feedback to the lecturer is "Student Evaluated Teaching (SET)”.

\section{Student Evaluated Teaching}

The need for greater accountability and improvement in the quality of teaching has become a major issue in $\mathrm{HE}$ in recent years (Coaldrake \& Stedman, 1998; Ballantyne et al., 2000). Therefore SET has become an integral part of HE's approach to maintaining teaching standards via a summative method: to gain data for administrative purposes, to provide information to students and to meet government guidelines; and a formative purpose: giving diagnostic feedback to lecturers about their teaching effectiveness (Marsh, 1987). SET is often the only measure of teaching effectiveness (Perry, 1997), so it is of paramount importance that the students give meaningful input. Literature however, suggests that SET is currently not fulfilling all its objectives as there doesn't appear to be a consensus as to what "effective teaching" includes (Shelvin et al., 2000). For example, Lowman and Mathie (1993) identifies lecturers' effectiveness, as comprising 1 intellectual excitement; and 2 interpersonal rapport; whilst Swartz et al. (1990) view it as composing: a) clear instructional presentation; and b) good management of student behavior. However in reality it's probably all of these items compounded with others such as encouraging students to have self worth (Covington, 1997), etc. Other problems with this system relates to the validity of the student evaluations as it is human nature to be subjective in voting, for example Shelvin et al. (2000) found that student evaluation frequently measures other factors such as $63 \%$ of the variance of the "lecturer effectiveness" score being accounted for by charisma.

Therefore HE establishments are wrong if they quantify teaching effectiveness on SET, or see students as customers, and shape their educational provision to meet their wishes or evaluations, as students objectives centre around getting the highest grades with the least amount of effort, or time (Chadwick \& Ward, 1987). Therefore good lecturers who use techniques to promote deep approaches to learning, which are by their nature, often harder work and more difficult tasks than surface approaches, may be looked upon less favorably than a teacher who "spoon feeds" information to the students (Platt, 1993).

The author has some unpublished data from staff and students at the University of Nottingham where she is based regarding the SET procedure. Significantly more students than staff thought the SET aimed to maintain/improve teaching standards, and to help initiate dialogue between the staff and students. Although is within the SET remit, the fact that staff are less likely to agree with these statements, means that the SET is not fulfilling its capabilities. Another telling analysis is that SET procedures do not seem to be followed, such as students are significantly less likely to believe that enough time has been set aside for this task, and that the feedback loop is not closed with dialogue from the lecturer to the students. Due to the lack of feedback, it appears that the students believe that SET is just 
to fulfill government requirements, although they maintain that teaching needs to be evaluated significantly more than the staff. So it appears that students value this process, but become disillusioned by the lack of feedback/impact, and not giving enough time to complete the form thoughtfully.

\section{Classroom Assessment Techniques}

The use of Classroom Assessment Techniques (CATs) is one way of resolving all of these problems. CATs offer an egalitarian and productive method of student evaluation, gives the opportunity for immediate formative feedback to both students and staff, and is also a formative assessment, therefore promotes deep learning techniques, and thus enhancing knowledge and motivation. CATs were first presented and described in detail in a book by Angelo and Cross in 1993. CATs are quick and simple activities which are designed to give both the lecturer and the students' useful, immediate feedback. They also assess the teaching-learning process rather than other confounding issues such as the charisma of the lecturer, or how easy the course is. They are defined as "small-scale assessments conducted continually in college classrooms by disciplinebased teachers to determine what students are learning in that class”, (Cross \& Steadman, 1996: p. 8).

CATs are sometimes called test-feedback cycles, and implementation of them allows teachers and students to share, on a regular basis, their conceptions about both the goals and processes of learning (Stefani \& Nicol, 1997) thereby opening up dialogue opportunities. They are usually not graded to enable the student to interact with the feedback, rather than become obsessed with the grade. However some authors argue that even making CATs count for $1 \%$ of the final grade will encourage students to take them seriously (Enerson et al., 2007). CATs rely on self-assessment, thus promoting the internal resources necessary for lifelong learning, and autonomy which enhances the learning process. In an evaluation of CATs use forty-five out of forty-six faculties in a university setting reported that there were no negative experiences associated with their use of CATs (Catlin \& Kalina, 1993), although there is still some debate regarding their efficacy as Cottell \& Harwood (1998) found no difference in grades, participation, or perceptions of learning between students who used CATs and those who didn't.

There are various types of CATs one can adopt (Table 2) although perhaps the most commonly used one is the "one-minute paper," where students are asked to write down answers to questions such as, "What was the most important thing you learned during this class?" or "What questions do you still have on this topic?" This type of technique enables the lecturer to discover how the students are processing and synthesizing the presented material as well as which points need to be reiterated or elaborated on before progressing. Therefore this method assesses student knowledge and also offers the lecturer immediate feedback regarding whether the students have grasped the most salient pieces of information from the lecture giving an opportunity to recap on any misunderstood items. Although, arguably, some CATs could be regarded as summative in nature, such as the minute paper, because of the immediate feedback and dialogue ensuing, they therefore become formative. CATs differ from tests and other forms of student assessment in that it provides timely opportunity for course improvement, with the goal of understanding the students' learning and therefore improving teacher effectiveness. Another benefit of this system is

Table 2.

Examples of CATs (adapted from a table on the National Teaching and Learning Forum, 2008).

\begin{tabular}{|c|c|c|c|}
\hline CAT & Method & Feedback & Effort \\
\hline Knowledge probe & $\begin{array}{l}\text { At the beginning of class as } \\
\text { students to answer preset questions (open, or } \\
\text { multiple choice) to assess students existing } \\
\text { knowledge. }\end{array}$ & $\begin{array}{l}\text { If multiple choice, use vote pads for } \\
\text { immediate discussion. Note any } \\
\text { weaknesses in knowledge for } \\
\text { elaboration. If open ended, could also } \\
\text { utilize peer assessment. }\end{array}$ & $\begin{array}{l}\text { Prep: low } \\
\text { In class: medium } \\
\text { Analysis: low }\end{array}$ \\
\hline Minute paper & $\begin{array}{l}\text { At the end of class ask student to write } \\
\text { "what is the most important point you } \\
\text { learned today?” and "What is the least clear } \\
\text { to you?” }\end{array}$ & $\begin{array}{l}\text { Collect and review responses. } \\
\text { Ensure that they have obtained the } \\
\text { correct message. In the next class } \\
\text { comment on the findings. Or, ask for } \\
\text { peer review and swop with partner. } \\
\text { Discuss any discrepancies. }\end{array}$ & $\begin{array}{l}\text { Prep: low } \\
\text { In class: low if collected, higher } \\
\text { if peer assessed } \\
\text { Analysis: low }\end{array}$ \\
\hline One-sentence summary & $\begin{array}{l}\text { Can be used at any time during class to test } \\
\text { knowledge about an important topic you } \\
\text { expect them to be able to summaries. }\end{array}$ & $\begin{array}{l}\text { Ensure the students have the } \\
\text { message. Can be done with a vote pad. }\end{array}$ & $\begin{array}{l}\text { Prep: low } \\
\text { In class: low } \\
\text { Analysis: low }\end{array}$ \\
\hline Directed paraphrasing & $\begin{array}{l}\text { Ask students to write a layman's summary } \\
\text { of any principle taught. This assesses their } \\
\text { ability to comprehend and transfer concepts. }\end{array}$ & $\begin{array}{l}\text { Peer or teacher assessed. Ensure the } \\
\text { salient points are covered. }\end{array}$ & $\begin{array}{l}\text { Prep: low } \\
\text { In class: medium } \\
\text { Analysis: medium }\end{array}$ \\
\hline Application cards & $\begin{array}{l}\text { Ask students to write down on real-world } \\
\text { application for a theory, principle or } \\
\text { procedure you have just covered. }\end{array}$ & $\begin{array}{l}\text { Collect and pick out a broad range of } \\
\text { examples to present to the class. Or } \\
\text { peers assess and discuss. }\end{array}$ & $\begin{array}{l}\text { Prep: low } \\
\text { In class: low } \\
\text { Analysis: med }\end{array}$ \\
\hline Muddiest point & $\begin{array}{l}\text { Ask students to write down the “muddiest } \\
\text { point” of the lecture, i.e., the concept they } \\
\text { feel they haven't understood. }\end{array}$ & $\begin{array}{l}\text { Collect written answers or get them to } \\
\text { discuss with their peers. Or have them } \\
\text { vote on predetermined items using } \\
\text { hand held voting systems }\end{array}$ & $\begin{array}{l}\text { Prep: low } \\
\text { In class: medium } \\
\text { Analysis: low }\end{array}$ \\
\hline
\end{tabular}


that there is very little time investment when compared to more traditional assessment such as essays or exams, especially when one bears in mind the time taken to provide feedback.

This method also fosters open dyadic communication and good rapport. CATs can be used within any size of classroom, large lectures or small seminars, and can personalize learning and lend themselves to peer led teaching/feedback. They have also been used in e-learning/distance formats (Henderson, 2001) and so are extremely versatile. They are well suited to the advent of the Interactive Voting Systems that many universities have adopted. These are systems that can be built into PowerPoint presentations and which use individual voting pads. The lecturer can then build a CAT into their presentation, ask the students to vote with their key pad and the system will then calculate the results immediately, presenting them on the screen for the lecturer and students to analyze. Mobile phones and SMS technology have also been shown to work when used in this manner (Markett et al., 2006). Using media in this way can enhance the learning experience as it is interactive therefore promoting deep learning. For example, Laurillard (1996) claims that by changing the media used in class, the student activity is changed and hence improves the learning situation i.e. "pedagogical re-engineering" (enhancing learning by changing the balance or combination of the components used) (Collis, 1996).

\section{Case Study}

In the author's own teaching, she has used CATs with great effect. In a module consisting of approximately 10 lectures, she built in around 5 CATs. The students were not told which lectures the CATs would appear in prior. This ensured that attention was maintained throughout the module. She used a CAT when there was an important theory/fact for the students to understand due to the ensuing lectures/work developing on from it. As she wanted to make the use of CATs fun, she decided not to mark them, but rather got students to debate around the topics with students next to them. Dependent upon when the author needed feedback about her teaching, and which important theory the students needed to grasp, informed which CAT was used, and also where in the lecture. She found that using voting systems built into the PowerPoint presentation engaged the students and gave immediate feedback about whether they were correct or not. She also found that students discussing CATs in small groups, such as the one-sentence summary promoted deep learning. The students would then write down the agreed answer on a card anonymously which were then collected so that the author would get feedback regarding the effectiveness of her teaching.

With virtual learning environments (VLE) become more integrated into HE teaching, the author has also used CATs within the VLE used at the University of Nottingham. Alongside putting the PowerPoint slides and associated handouts up online, she has found success with an online survey replicating the knowledge probe CAT which asks one or two questions. It appears that the students value the engagement that using CATs offer, as the SET scores for her modules are always high and the pass rate of assessments are also high. The author also values the timely feedback on her teaching, so she can detect any problems early and give her opportunity to approach the theory in another manner, encourage peer teaching and learning, and identify key items of literature for them.

Another area she is currently exploring is working with small groups of students, so that they can design a suitable CAT for their target lecture. This involves meeting with the students shortly after their target lecture to discuss what they believe were the salient points and how they might assess the student's grasp of them. Working in their small groups they then design the CAT they feel would be the most appropriate (or design a new one), and carry it out at the start of the next lecture. They then collect the data back from the students and review it in their groups and report back to the author with any deficits in the learning identified. If any deficits are observed, some ideas from them about how these could be remedied such as resources which they could be referred to for further reading, typed up study notes, etc. are required from them. These resources are then given back to the class by the students, and feedback obtained e.g. whether other students knew of any further useful resources which were omitted, etc. To ensure commitment, the author has allocated 5\% to this task. This task not only promotes deep learning (to both "teachers” and "students"), but also encourages team work and hones their teaching/public speaking ability. For the author, it also ensures some student designed teaching, from which she can also learn. Although it seems to have worked out well, it does take some organization, such as getting students to form groups, and staggering them throughout the module. However the feedback from all students was positive so far.

\section{Conclusion}

CATs encourage the view that teaching and learning is a formative process that evolves over time. By being able to react swiftly to student answers, they provide the opportunity for immediate feedback to the lecturer which can be promptly acted upon, therefore giving the chance to the teacher to close the feedback loop. It encourages self-assessment by the student and reflection amongst both the lecturers and students. However care must be taken in choosing the appropriate CAT and also allowing enough time in class to ensure that they are worthwhile. It may also be a good idea to give the CATs a nominal grade of $5 \%$ or $10 \%$ to ensure that the students value them.

Tips for successful use of CATs (Angelo \& Cross, 1993):

- Don't ask for feedback on things you can’t or won't change;

- Don't collect more feedback than you can analyze and respond to by the next lecture;

- Before you use a CAT, ask yourself: How might responses to this question(s) help me and my students improve? If you can't answer that question, don't do the assessment;

- Don't use too many different CAT techniques in one semester. Student responses are more useful when the students are comfortable with a particular technique and understand it (Martin, 2011).

\section{REFERENCES}

Angelo, T. A. (1991). Classroom research: Early lessons from success. San Francisco, CA: Jossey-Bass.

Angelo, T. A., \& Cross, K. P. (1993). Classroom assessment techniques-A handbook for college-teachers. San Francisco, CA: Jossey-Bass Publishers.

Ballentyne, R., Borthwick, J., \& Packer, J. (2000). Beyond student evaluation of teaching: Identifying and addressing academic staff development needs. Assessment and Evaluation in Higher Education, 
25, 211-236.

Barnett, R. (2007). Assessment in Higher Education. In D. Boud, \& N. Falchicov (Eds.), Re-thinking assessment in higher education: Learning for the longer term (pp. 29-40). London: Routledge Taylor and Francis.

Biggs, J. (1987). Student Approaches to Learning and Studying. Hawthorn, VIC: Australian Council for Educational Research.

Biggs, J. (1993). What do inventories of students' learning process really measure? A theoretical review and clarification. British Journal of Educational Psychology, 83, 3-19. doi:10.1111/j.2044-8279.1993.tb01038.x

Black, P., \& William, D. (1998). Assessment and classroom learning. Assessment in Education, 5, 7-74. doi:10.1080/0969595980050102

Catlin, A., \& Kalina, M. (1993). What Is the Effect of the Cross/Angelo Model of Classroom Assessment on Student Outcome? A Study of the Classroom Assessment Project at Eight California Community Colleges. Sacramento, CA: California Community College Chancellor's Office.

Chadwick, K., \& Ward, J. (1987). Determinants of consumer satisfaction with education: Implications for college \& university administrators. College and University, 2, 236-246.

Coaldrake, O. P., \& Stedman, L. (1998). On the brink: Australia's universities confronting their future. St. Lucia, QLD: University of Queensland Press.

Collis, B. (1996). Tele-learning in a Digital World: The future of distance learning. London: International Thomson Computer Press.

Covington, M. V. (1997). A motivational analysis of academic life in college. In R. P. Perry, \& J. C. Smart (Eds.), Effective teaching in higher education: Research and practice (pp. 61-100). New York: Agathon Press.

Cross, P., \& Steadman, M. (1996). Classroom Research: Implementing the scholarship of teaching. San Francisco, CA: Jossey-Bass.

Dochy, F., \& McDowell, L. (1997). Assessment as a tool for learning. Studies in Educational Evaluation, 23, 279-298. doi:10.1016/S0191-491X(97)86211-6

Dweck, C. (1999). Self-Theories: their role in motivation, personality and development. Philadelphia, PA: Psychology Press.

Enerson, D. N., Plank, K. M., \& Johnson, R. N. (2007). An introduction to classroom assessment techniques. University Park, PA: Penn State.

Freeman, R., \& Lewis, R. (1998). Planning and implementing assessment. London: Kogan Page.

Gibbs, G. (2006). Why assessment is changing. In C. Bryan, \& K. Clegg (Eds.), Innovative assessment in higher education (pp. 11-22). Abingdon: Routledge.

Henderson, T. (2001). Classroom assessment techniques in asynchronous learning networks. The Technology Source. URL (last checked 12 October 2012).

http://ts.mivu.org/default.asp?show=article\&id=1034

Juwah, C., Macfarlane-Dick, D., Matthew, B., Nicol, D., Ross, D., \& Smith, B. (2004). Enhancing student learning through effective formative feedback. The Higher Education Academy. URL (last checked 12 October 2012).

http://www.heacademy.ac.uk/assets/documents/resources/database/id 353_senlef_guide.pdf

Laurillard, D. (1996). How should UK higher education make best use of new technology? Glasgow: Association for Learning Technology.

Lowman, J., \& Mathie, V. A. (1993). What should graduate teaching assistants know about teaching? Teaching of Psychology, 20, 84-88. doi:10.1207/s15328023top2002_4

Markett, C., Sanchez, I. A., Weber, S., \& Tangney, B. (2006). Using short message service to encourage interactivity in the classroom. Computers \& Education, 46, 280-293. doi:10.1016/j.compedu.2005.11.014

Marsh, H. W. (1987). Students' evaluation of university teaching: Research findings, methodological issues and directions for future research. International Journal of Educational Research, 11, 253-388. doi:10.1016/0883-0355(87)90001-2

Martin, M. B. (2011). Classroom assessment techniques designed for technology. URL (last checked 29 August 2012). http://online-course-design.pbworks.com/f/Classroom+Assessment+ Techniques+Designed+Technology.pdf

Marton, F., \& Saljo, R. (1976). On qualitative differences in learning-1: Outcome and process. British Journal of Education Psychology, 46, 4-11. doi:10.1111/j.2044-8279.1976.tb02980.x

Moore, M. G. (1989). Editorial: Three types of interaction. The American Journal of Distance Education, 3, 1-6.

doi:10.1080/08923648909526659

National Teaching and Learning Forum (1998). Classroom assessment techniques (2nd ed.). New York: Jossey-Bass. www.ntlf.com/html/lib/bib/assess.htm

Nicol, D. J., \& Macfarlane-Dick, D. (2006). Formative assessment and self-regulated learning: A model and seven principles of good feedback practice. Studies in Higher Education, 31, 199-218. doi:10.1080/03075070600572090

Norton, L. S., Tilley, A. J., Newstead, S. E., \& Franklyn-Stokes, A. (2001). The pressures of assessment in undergraduate courses and their effect on student behaviors. Assessment \& Evaluation in Higher Education, 26, 269-284. doi:10.1080/02602930120052422

Perry, R. P. (1997). Teaching effectively: Which students? What methods? In R. P. Perry, \& J. C. Smart (Eds.), Effective teaching in higher education: Research and practice (pp. 154-170). New York: Agathon Press.

Platt, M. (1993). What student evaluations teach. Perspectives in Political Science, 22, 29-40. doi:10.1080/10457097.1993.9944516

Ramsden, P. (1992). Learning to teach in higher education. London: Routledge. doi:10.4324/9780203413937

Shelvin, M., Banyard, P., Davies, M., \& Griffiths, M. (2000). The validity of student evaluation of teaching in higher education: Love me, love my lectures? Assessment and Evaluation in Higher Education, 25, 397-405. doi:10.1080/713611436

Stefani, L., \& Nicol, D. (1997). From teacher to facilitator of collaborative enquiry. In S. Armstrong, G. Thompson, \& S. W. Brown (Eds.), Facing up to radical changes in universities and colleges (pp. 131140). London: Kogan Page.

Swartz, C. W., White, K. P., \& Stuck, G. B. (1990). The factorial structure of the North Carolina teacher performance appraisal instrument. Educational and Psychological Measurement, 50, 175-185. doi:10.1177/0013164490501021 